\title{
The Role of Exercise in Pediatric and Adolescent Cancers: A Review of Assessments and Suggestions for Clinical Implementation
}

\author{
Riggs Klika $^{1,2}$ D, Angela Tamburini ${ }^{3}$, Giorgio Galanti ${ }^{2}$, Gabriele Mascherini ${ }^{2}$ \\ and Laura Stefani ${ }^{2, *}$ \\ 1 Chair American College of Sports Medicine Special Interest Group on Cancer, \\ Sports and Exercise Medicine Center, University of Florence, Largo Brambilla 3, 50134 Florence, Italy; \\ riggsklika@gmail.com \\ 2 Sports and Exercise Medicine Center, Clinical and Experimental Department, School of Sports Medicine, \\ University of Florence, Largo Brambilla 3, 50134 Florence, Italy; giorgio.galanti@unifi.it (G.G.); \\ gabriele.mascherini@unifi.it (G.M.) \\ 3 The Meyer Hospital, University Hospital (AOU Meyer), Viale Pieraccini 24, 50139 Firenze, Italy; \\ angela.tamburini@meyer.it \\ * Correspondence: laura.stefani@unifi.it; Tel.: +39-34-7768-9030
}

Received: 6 December 2017; Accepted: 10 January 2018; Published: 14 January 2018

\begin{abstract}
In the European Union, five-year survival rates for childhood cancer patients are approaching $72-80 \%$, which is a testament to better diagnostics and improved treatment. As a result, a large proportion of childhood cancer patients go on to live productive lives well past reproductive age. While this is encouraging, childhood cancer treatment is accompanied by multiple long-term adverse effects on physical and mental wellbeing. While there are several approaches to address mental health, reproductive integrity, secondary pathologies, and recurrence, in order to optimize quality of life in childhood cancer patients, exercise and nutrition should also be considered. It is clear that physical activity plays an important role in the prevention and reduction of long-term adverse side effects associated with cancer treatment in both children and adults. However, the current exercise guidelines for cancer survivors are based on adult data and accordingly are not appropriate for children. As children and adults are markedly different, including both the pathophysiology of cancer and exercise response, treatment plans incorporating exercise for children should be age-specific and individually tailored to both reduce the development of future comorbidities and enhance physical health. The purpose of this paper is to review the predominant cancer types and effects of cancer treatment in children, describe several special considerations, and propose a framework for assessment and exercise guidelines for this population.
\end{abstract}

Keywords: cancer; children growth and maturation; physical activity; exercise; assessment

\section{Introduction}

The International Agency on Cancer Research estimates that, globally, 300,000 children aged 0-19 years will be diagnosed with cancer each year [1]. With current treatments, approximately $72-84 \%$ of these children will survive five or more years in the EU and USA, and to a much lesser degree $(\sim 10 \%)$ in developing countries [2-4]. While there is a disparity among survival rates in various countries, it is clear that survival rates for childhood cancer patients are improving [3]. Recent estimates from several Western countries put the proportion of long-term childhood cancer survivors (CCS) between $0.1 \%$ and $0.15 \%$ of the general population, implying that one in every $1000-1650$ persons is a childhood cancer survivor [3]. In Italy about 1150 new CCS will be added to the population yearly 
based on an estimate that $75 \%$ of children treated on current protocols for childhood ( $0-19$ years) cancer will become long-term survivors ( $>5$ years) [5]. While increased survival rates are encouraging, the advancements in treatment for childhood cancer patients are unfortunately often accompanied by several late adverse events (LAE).

In children treated for cancer, LAE include impaired growth [6], cognitive dysfunction [7,8], diminished neurological function [9], cardiopulmonary compromise [10,11], musculoskeletal disturbances [10], and secondary malignancy [12,13]. As a result, adult survivors of childhood cancer may suffer from cardiomyopathy, heart valve and conduction disorders [14,15], increased cardiovascular risk factors including hypertension, dyslipidemia [16-18], and obesity [19,20], pulmonary disorders [21,22], endocrine disorders [23] including hypothalamic-pituitary-adrenal disorders [24], diabetes mellitus [25], ovarian and Leydig cell dysfunction [26], and hypothyroidism [27]. Survivors of childhood cancer are also at increased risk for neurocognitive and neurosensory impairment including ocular degeneration, hearing loss and neuropathy [28-31], metabolic disturbances (abnormal blood counts, liver and kidney dysfunction, and osteoporosis) [28-30,32,33], transfusion-associated infections [30], and increased risk of subsequent neoplasm [14]. A major concern is that chronic LAE may increase in frequency and severity over time, and interact adversely with the normal ageing process, resulting in increasing and clinically significant impairment of vital organ systems during adulthood at a younger age than normal, and an increased risk of premature major illness or death [34-37].

As with adult cancer patients, childhood cancer patients decrease their physical activity levels during and after cancer treatment, which may exacerbate LAE $[10,17,36,38]$. Physical activity is positively related to body weight management, cardiopulmonary fitness, musculoskeletal integrity, mental well-being, and decreased risk of premature mortality in adult cancer patients [38], while reduced physical activity is associated with decreased cardiopulmonary function, aerobic fitness, and motor-skill development/integrity and increased cachexia and cancer-related fatigue [18]. As a result of the numerous LAE related to pediatric cancer treatment, an interest in using exercise as a therapeutic measure to attenuate or reverse many cancer-related LAE in the pediatric population has surfaced. While comparatively less studied, the research suggests that there is a positive effect of physical activity on organ system function, fatigue, and physical well-being in children during and after cancer treatment [39-49]. It is clear that children who exercise can increase aerobic fitness and strength, with the latter a result of neuromuscular adaptations rather than skeletal muscle hypertrophy. The differences in the exercise training response between adults and children are most likely related to children having fairly well developed aerobic systems and relatively immature anaerobic systems [50].

What is less clear in childhood cancer patients is the physical activity level needed to increase physical function/health during and after treatment while not adding to an already elevated stress burden, which could conceivably be detrimental to the child's health. In adults, it appears that the most effective strategies for increasing physical activity levels after treatment are individualized programs that are initiated under supervision and are later adopted into life-style behaviors in an unsupervised setting $[38,51]$. It is not clear whether this is an ideal strategy for childhood cancer patients, but it appears that most current pediatric cancer exercise programs implement this approach [39,40].

In adult exercise oncology, the long-term strategic aim is to ensure that every cancer survivor receives optimal long-term care that increases their health and survival [38]. The goal is no different in the pediatric population [52-55], but there are much fewer data available to draw conclusive and precise exercise guidelines. Therefore, the goal of this review is to examine pediatric cancers, associated cancer treatments, and late adverse events and review emerging knowledge on pediatric exercise oncology. A summary of current exercise practices for childhood cancer patients is provided and suggestions for clinical assessment and a three-tiered rehabilitation plan are offered. 


\section{Types of Childhood Cancer}

Childhood cancers make up less than $1 \%$ of all cancers diagnosed each year but still rank as the second-leading cause of death for children 1-14 years; they differ from adult cancer with regards to incidence and prevalence as well as etiology [2]. In children, typical cancers include acute lymphocytic leukemia (ALL) and acute myelogenous leukemia (AML), which comprise about $30 \%$ of all cancers in children [2]. ALL and AML are characterized by abnormal proliferation of leukocytes and reduction of normal blood cells. Leukemia causes bone and joint pain, fatigue, weakness, pale skin, bleeding or bruising, fever, weight loss, and other symptoms. Because acute leukemia grows quickly, chemotherapy is typically initiated soon after diagnosis.

Brain and spinal cord tumors are the second most common cancer in children, making up approximately $26 \%$ of childhood cancers. Central nervous system tumorigenesis starts in the lower parts of the brain, such as the cerebellum or brain stem, and may cause headaches, nausea, vomiting, blurred or double vision, dizziness, seizures, and trouble walking or handling objects. Spinal cord tumors are less common than brain tumors in both children and adults [2,52]. About $6 \%$ of childhood cancers are neuroblastomas, which can be found in a developing embryo or fetus. This cancer develops in infants and young children and is rarely found in children older than 10.

Wilms tumors (nephroblastoma) account for about $5 \%$ of childhood cancers and start in one, or rarely, both kidneys. They are most often found in children about 3-4 years old, and are uncommon in children older than six. They manifest as a swelling or lump in the abdomen and are characterized by fever, pain, nausea, or poor appetite.

Lymphoma (including both Hodgkin and non-Hodgkin lymphomas) starts in the lymphocytes, lymph nodes, or other lymph tissues such as the tonsils or thymus and can affect the bone marrow and other organs. Symptoms depend on where the cancer is located and can include weight loss, fever, sweats, fatigue, and swollen lymph nodes in the neck, axilla, or inguinal region. Hodgkin lymphoma accounts for about $3 \%$ of childhood cancers and is more common in early adulthood (age 15 to 40; usually people in their 20s) and late adulthood (after age 55) [2,53]. Hodgkin lymphoma is rare in children younger than five. Non-Hodgkin lymphoma makes up about $5 \%$ of childhood cancers. It is more likely to occur in younger children than Hodgkin lymphoma and is rare in children younger than three [2]. These cancers often grow quickly and require intensive treatment, but they also tend to respond better to treatment than most non-Hodgkin lymphomas in adults. Rhabdomyosarcoma is an aggressive and highly malignant form of cancer that develops from skeletal muscle cells that have failed to fully differentiate. This type of cancer can start nearly anywhere in the body, including the head and neck, groin, abdomen, pelvis, or in the appendages. It may cause pain, swelling, or both. This is the most common type of soft tissue sarcoma in children and makes up about $3 \%$ of childhood cancers [2].

Retinoblastoma is a rare cancer that develops from immature cells of the retina and accounts for about $2 \%$ of childhood cancers [2]. It usually occurs in children approximately two years old and is seldom found in children older than six. Osseous cancers (including osteosarcoma and Ewing sarcoma) account for about $3 \%$ of childhood cancers. Osteosarcoma is an aggressive malignant neoplasm of the bone that often causes bone pain that gets worse at night or with activity and produces localized swelling. Ewing sarcoma is a malignant bone tumor most often found in young teens. The most common origins of ES are the pelvis, thoracic cavity, or middle of the long leg bones [2].

\section{Treatments for Childhood Cancer}

Treatment for childhood cancer is based on the type and stage of the cancer. Types of treatment used for childhood cancer include: surgery, chemotherapy, radiation, hormone therapy, stem cell transplantation, and newer treatments such as targeted drug therapy and immunotherapy. Often, multiple treatments are indicated. Chemotherapy for CCS includes alkylating agents, antimetabolites, anthracyclines, plant alkaloids, antitumor antibiotics, taxanes, and monoclonal antibodies. Childhood cancers usually respond well to high-dose chemotherapy because of rapid cell turnover in children 
and are effective but often lead to more short- and long-term side effects [2]. In general, the more frequently recognized risk factors for long-term events in children include patient age at treatment, cumulative treatment dose, and the treatment schedule of radio- or chemotherapy [13,54].

\section{Late Adverse Events (LAE) in Childhood Cancer Patients}

The high survival rate in children and adolescents with malignancy is accompanied by a substantial risk of late adverse events (LAE) as a result of long-term radio- and chemotherapy. Chemotherapy for pediatric cancer suppresses the immune system and may interfere with normal growth, increasing susceptibility to infection and stunting or delaying musculoskeletal development during treatment [49]. Treatments may interfere with physiological growth and development in children and adolescents and have an important impact on health status later in life, while some late toxicities (e.g., pulmonary fibrosis, obesity, hypertension, cardiovascular disease) may cause premature death $[11,14,16,17,20,21,25,28,31]$. It has been estimated that $62 \%$ of adult survivors of childhood malignancy have $\geq 1$, and $38 \% \geq 2$, treatment-induced chronic health conditions, and $28 \%$ a severe or life-threatening problem such as cardiomyopathy [30]. Survivors of central nervous system tumors or hematopoietic stem cell transplantation are at particularly high risk $[8,30]$.

\section{Complications after Childhood/Adolescent Cancer Treatment}

CCS are potentially vulnerable to a variety of long-term therapy-related complications, and therefore lifestyle management is important in reducing LAE commonly present during adulthood. Physical and psychosocial adverse treatment effects can increase premature morbidity and mortality when compared to the general population, and therefore developing strategies for long-term follow-up of survivors of childhood cancer is essential $[29,48]$.

Among the most serious health complications in CCS following treatment are pulmonary and heart disorders $[3,30]$. Chronic pulmonary disease is the number one LAE following childhood cancer treatment, with $65.2 \%$ of those followed up having abnormal pulmonary function [30]. Bleomycin toxicity resulting in pulmonary fibrosis, radiation to the lungs, thoracotomy, and busulfan treatment increase the risk of abnormal pulmonary function in CCS. Both restrictive and obstructive lung disease may occur, while bronchiectasis may result from previous lower respiratory tract infections.

Cardiac abnormalities have been reported in $56 \%$ of survivors of childhood cancer treatment, who are 5-15 times more likely to experience heart disease than their siblings [17,30,44]. The major risk factors for the development of cardiac dysfunction are treatment with anthracyclines and/or radiotherapy to the heart. Vinca alkaloids and alkylating agents have also been implicated in cardiovascular complications, along with young age at treatment, female gender, and length of follow-up. Chemotherapy and radiotherapy increase cardiovascular disease in the form of coronary artery damage, myocardial failure, pericardial disease, valvular abnormalities, conduction disorders, and increased cardiovascular risk factors. Valvular regurgitation is common (56\%) in adult survivors of childhood cancer who have been previously exposed to radiotherapy, while systolic dysfunction is prevalent after exposure to anthracyclines or both treatments (6\%) [17]. Fifty percent of CCS reported being obese, $61 \%$ have dyslipidemia, and $23 \%$ are hypertensive-all increasing the risk of future cardiovascular disease [30].

In CCS, as well as adults who are survivors of childhood cancer, the risk of clinical metabolic syndrome is high [26]. Metabolic syndrome (MS) is characterized by a clustering of hypertension, dyslipidemia, type 2 diabetes or preclinical conditions, and obesity. MS is associated with a proinflammatory and pro-thrombotic state that may lead to atherogenic dyslipidemia. There is evidence that survivors exposed to cranial radiotherapy, prolonged steroid treatment, total body or abdominal irradiation, and those with hypogonadism or limitations in physical performance are at increased risk of glucose intolerance and MS.

Cancer treatment is also related to several acute or chronic renal complications. Nephrotoxicity may be due to glomerular or tubular damage, or both. Renal failure or the requirement for dialysis is 
an uncommon but serious late complication, occurring in $<1 \%$, but with a relative risk ratio estimated at about 8 [35]. The main risk factors for nephrotoxicity are the specific chemotherapy drugs received. For example, ifosfamide nephrotoxicity is more common in patients treated with a cumulative dose $>80 \mathrm{~g} \cdot \mathrm{m}^{-2}$. Platinum nephrotoxicity is more common in children treated with a higher cisplatin dose rate $\left(>40 \mathrm{mg} \cdot \mathrm{m}^{-2} \cdot \mathrm{day}^{-1}\right)$ or higher cumulative carboplatin doses and those treated at an older age.

Endocrine complications are similar in overall prevalence to cardiac abnormalities in CCS, occurring in $20-50 \%$ of survivors followed into adulthood [30]. Complications include hypothalamo-pituitary, thyroid, and gonadal dysfunction, bone disease, and metabolic disorders, which are associated with the tumor type and location and treatment. In addition to the effects of surgery or direct endocrine gland involvement by the malignancy, both radio- and chemotherapy may increase the risk of endocrine complications involving several glands. These are the most frequently reported complications of childhood cancer survivors, affecting between $20 \%$ and $50 \%$ of individuals who survive into adulthood. Most endocrine complications are the result of prior cancer treatments, especially radiotherapy. Survivors treated with radiotherapy to the head, neck, or pelvis, and those treated with total body irradiation or with alkylating agents, are at increased risk. Growth hormone deficiency is the most common anterior pituitary deficiency observed after standard cranial radiotherapy. It may manifest after a standard cranial radiotherapy dose $\geq 18 \mathrm{~Gy} ;>24 \mathrm{~Gy}$ the deficiency usually manifests within five years, while for doses in the range of 18-24 Gy the deficiency may become manifest after 10-15 years [49]. Other endocrine disorders in CCS include precocious puberty in young females treated for ALL, which is related to radiation of the hypothalmo-pituitary axis in the range 18-24 Gy.

Ovarian germ cell failure and loss of ovarian endocrine function occur concomitantly in females $[10,13,15,30]$. They may be due to pelvic, abdominal, or spinal radiation, total body irradiation, or alkylating agent chemotherapy. Age at treatment is important in predicting ovarian failure, since females treated at a younger age are less likely to develop ovarian failure, probably because of a higher number of primordial follicles at the time of treatment. Uterine morphology should be evaluated in females treated with pelvic or abdominal radiation, to assess the likelihood of embryonal implantation or completion of fetal development. The testis is sensitive both to chemotherapy and radiation [23]. Among chemotherapeutic agents, cumulative doses of alkylating agents and timing of treatment influence the risk of oligo/azoospermia. Damage to the germinal epithelium is estimated to occur after a testicular dose $<1.2 \mathrm{~Gy}$ either as direct testicular radiotherapy or during abdominal or spinal radiation or an inverted $Y$ field for Hodgkin disease (HD) treatment. Leydig cells are much more radioresistant and only doses >20 Gy (pre-pubertal patients) or >30 Gy (post-pubertal individuals) may result in complete primary hypogonadism. In contrast to females, age at treatment has minimal impact on testicular function.

The thyroid gland is sensitive to radiotherapy given either externally to the neck or targeted via thyroid metabolism. The functional changes after external beam radiation usually occur by six months but may become evident up to 20 years later, and comprise clinical or subclinical hypothyroidism, with a combined incidence of 20-30\% [6,7,16]. The morphological changes consist of benign lesions, primarily adenomas, and malignant lesions, with an average 6-fold increased risk compared to the normal population. The effect of radiotherapy on the thyroid gland is dose- and age-dependent, with younger children at a higher risk. A linear relationship with radiotherapy doses and late thyroid complications has been observed, but after doses $>30 \mathrm{~Gy}$ the cancer risk decreases, probably because of a cell-killing effect.

Long-term neurological toxicity is a common late adverse event reported in some large CCS cohorts, occurring in $27 \%$ of survivors, with a relative risk ratio of 3.3 compared to a sibling control group. CCS with central nervous system tumors are at the highest risk, followed by survivors of Hodgkin disease or acute leukemia [18]. There are several manifestations of central nervous system toxicity, including leukoencephalopathy, vasculopathy, radiation necrosis, myelopathy, and secondary tumors, with a wide variety of clinical sequelae threatening life or greatly impairing the survivor's quality of life. Neurocognitive impairment is common in CCS being reported as high as 48\% [30]. 
Other impairments include ocular (28\%), vestibular/hearing loss (62\%), and neuropathy (22\%) [54]. The major cause of deafness in survivors of childhood malignancy is platinum chemotherapy. Both higher cumulative cisplatin dose and younger age at treatment predict a higher risk of deafness, with a total dose $>400 \mathrm{mg} \cdot \mathrm{m}^{-2}$ and age $<5$ years associated with development of bilateral sensorineural hearing loss in $40 \%$ of children. The consequences of deafness in children include delayed speech development and impaired educational/social functioning, especially in younger children.

Specific treatment-related complications occur in very young cancer patients. Craniofacial and dental complications are more prevalent in patients treated at a young age. The younger the child and the higher the radiation dose, the more pronounced the growth impairment. Radiotherapy to the face or brain may lead to hypoplasia of the irradiated area. As normal growth occurs, the deformity becomes progressively more pronounced. However, the most evident effect on linear growth is seen when radiotherapy is given before skeletal maturation has occurred [7]. Bone irradiation $>20 \mathrm{~Gy}$, especially near long-bone growth plates, leads to reduced bone growth and potentially asymmetric limb growth. If the spine is involved in the radiation field, vertebral bodies will display impaired growth, leading to a reduced adult height, with disproportion between standing and sitting height [32]. Scoliosis may result from soft tissue fibrosis secondary to radiotherapy to paravertebral tissues/organs. Avascular necrosis of bone may occur either during or after therapy, particularly with radiation and/or prolonged steroid treatment, and usually affects joints in long bones, causing pain and functional impairment.

Survivors of hematopoietic stem cell transplant (HSCT) are at particularly high risk of late adverse complications, with $>90 \%$ suffering from at least one and $>70 \%$ from at least three chronic conditions [8]. Patients treated with total body irradiation are at the highest risk of late toxicity, and high-dose chemotherapy is an additional potent risk factor. Additive and potentially synergistic damage results from numerous other factors, including previous treatment given before transplant, the development of other serious complications after HSCT, potentially toxic supportive care drugs, and especially chronic graft vs. host-disease, which may affect any organ, tissue, or body system. Chronic graft versus host-disease occurs in up to $30 \%$ of HSCT patients, with multiple potential sequelae including organ and tissue damage, as well as functional impairment and the potential adverse effects of immunosuppressive drugs.

Surgical complications and late physical effects must be considered in CCS. Orthopedic treatment for cancer may result in partial or total bone damage and prosthetic implantation [15]. As a result of surgery, posture, gait, and physical activity levels are affected [32]. The management of the correct/neutral posture and proper motor skill development need to be emphasized and eventually modified to follow the disease progression. Although the quality of life of these surgical patients in domains other than physical functioning is as high as that seen in controls, there is a life-long need for many patients to have continued contact with health services, e.g., for prosthetic reasons or post-surgical complications.

Last, the psychosocial consequences of childhood cancer and LAE should be considered. It is clear that psychological or social consequences interfere with quality of life (QoL), which comprises elements of physical, functional, social, and psychological health [21,22,47,55-58]. QoL may be affected by the level of integration into society, as measured by the survivors' probability (compared to age and sex-matched general population peers) of securing employment or health insurance, or of marrying [57]. It is important that the public ensures that cancer survivors have equal access to education, jobs, insurance, and medical care. The Children's Oncology Group (COG) www.survivorshipguidelines.org has developed long-term follow-up guidelines for survivors of childhood cancers [59]; however, a specific path for the transition from hospital-based care to home-based rehabilitation has not been clearly defined.

\section{Guidelines for Assessment}

The choice of assessment protocols for CCS depends on the specific questions that one may ask and, as a rule, one should test those physiological functions that are most likely to yield relevant 
clinical and functional information. A summary of potential test battery items is presented in Table 1 . At a minimum, practitioners should be regularly measuring body dimensions including stature, weight, head circumference, and an index of body composition (e.g., BMI, skinfolds at four sites (triceps, biceps, subscapular and iliac crest, and circumferences (arm relaxed and flexed, calf) for muscle mass development)) following international standards measurement sites and procedures $[60,61]$. Comparisons can be made by sex, and to population-specific normative data. Tracking changes in stature, weight, weight-to-stature ratio, and body mass index will provide insight into nutritional status and normal body growth [62]. Body composition analysis using bioelectrical impedance or DXA scanning may provide more detailed information on total body water distribution and fat versus fat-free mass components; however, due to the large variability in body composition during growth, the clinical use of these tools is questionable. Additionally, errors in interpreting DXA results may generate considerable parental concern and can result in costly and unnecessary use of pharmacologic agents and restrictions on physical activity [63].

Table 1. Potential assessment items for pediatric cancer patients.

\begin{tabular}{|c|c|}
\hline Domain Being Measured & Item \\
\hline \multirow{5}{*}{ Body size and nutritional status } & Height (cm) \\
\hline & Weight (kg) \\
\hline & BMI \\
\hline & Head Circumference \\
\hline & Skinfolds (mm) \\
\hline \multirow{4}{*}{ Motor Skill } & Posture \\
\hline & Gait \\
\hline & Balance \\
\hline & Motor skill proficiency \\
\hline \multirow{2}{*}{ Flexibility } & Sit and Reach \\
\hline & Ankle dorsiflexion \\
\hline \multirow{3}{*}{ Performance Level } & Hand grip dynamometry (kg) \\
\hline & TUG-3 m (s) \\
\hline & 30 s Chair stand (\# of successful stands) \\
\hline \multirow{3}{*}{ Cardiovascular Fitness } & $\mathrm{PWC}_{150}$ \\
\hline & Echocardiography \\
\hline & $\mathrm{CPET}\left(\mathrm{VO}_{2}\right.$ peak $)\left(\mathrm{mL} \cdot \mathrm{kg}^{-1} \cdot \mathrm{min}^{-1}\right)$ \\
\hline Pulmonary Function & Spirometry $\left(\mathrm{FEV}, \mathrm{FEV}_{1}\right)$ \\
\hline Quality of Life & PCQL Inventory \\
\hline
\end{tabular}

References for each test item can be found in the text. TUG: timed get up and go; PWC: power work capacity; FEV: forced expiratory volume, FEV1: forced expiratory volume in $1 \mathrm{sec}$, PCQL: pediatric cancer quality of life.

\section{Echocardiographic Assessment}

Echocardiography represents the best non-invasive method for obtaining sufficient information in CCS as part of a complete clinical evaluation to clear the patient for physical activity. Echocardiographic stress testing is considered the standard of care in contemporary assessment regarding left ventricular performance, pulmonary pressure measurement, and valve behavior, and should be considered for all CCS $[30,31,64]$. In addition to the standard echocardiographic measures (i.e., systolic and diastolic data of the left and right ventricles), velocity parameters (tissue velocity imaging or TDI) and deformation measures (strain) are now routinely used in the assessment and management of cancer patients participating in regular physical activity and more strenuous sports [64-68]. Echocardiography, as an advanced tool in cardio-oncology, can be used to detect early-stage myocardial damage and its applications are now being used in the pediatric population [68]. 


\subsection{Cardiopulmonary Exercise Testing (CPET)}

In healthy children, or those with a cardiopulmonary disease, cardiopulmonary exercise testing is considered the gold standard for assessing aerobic fitness and when equipment accommodations should be made for the child (e.g., smaller cycle ergometer, child-specific graded exercise protocols) [50]. CPET is both reliable and valid in the pediatric population [69]. CPET can provide information about aerobic fitness, hemodynamic response to exercise, metabolic response, and ventilatory thresholds. Data obtained from symptom-limited CPET are sufficient to establish exercise intensity guidelines for CCS. Variables measured during CPET include electrocardiogram, power or workload (speed and grade), heart rate, oxygen saturation, blood pressure, and a rating of perceived exertion (RPE). A Borg scale of 6-20 or modified Borg scale of 1-10 can be used to evaluate RPE [70]. Post-CPET, monitoring should be continued for 5-10 min and terminated when the heart rate has returned to $110 \%$ (or lower) of the pre-exercise testing heart rate.

\subsection{Power Work Capacity $\left(P W C_{150}\right)$}

Power work capacity is a submaximal cycle ergometer test whereby the child is asked to pedal a cycle ergometer at a specific power that will elicit a heart rate of 150 beats $\cdot \mathrm{min}^{-1}$. Power is recorded as the outcome measure. Changes in $\mathrm{PWC}_{150}$ reflect cardiovascular fitness and can be administered on a regular basis without the specialized metabolic analyzers needed for CPET [69].

\subsection{Pulmonary Function Testing (PFT)}

PFT should include spirometry that measures forced vital capacity (FVC) and forced expiratory volume in $1 \mathrm{~s}\left(\mathrm{FEV}_{1}\right)$ in order to screen for restrictive or obstructive airway disease caused by radiation and pulmonary fibrosis. Preliminary screening should be followed by referral to pediatric pulmonary specialists if abnormal values are detected and prior to the CCS participating in structured physical activity.

\subsection{Motor and Skill Assessment}

As a component of physical function, an age-appropriate motor skill assessment should be made. In children 0-2 years of age, the Bayley Infant Scoring system for neurocognitive development has been routinely used and is both reliable and valid [71]. If the child has developed basic movement skills (walk, run, throw, skip, hop, leap) then an assessment of fundamental movement skills may be appropriate [72,73]. Nauman et al. have reported the performance efficiency on the sprint run, vertical jump, side gallop, leap, catch, kick, and overarm throw efficacy in childhood cancer patients, which discriminated between oncology patients and health controls [72].

Posture and gait analysis will provide information on orthopedic dysfunction, equilibrium, skeletal musculoskeletal integrity, and neuromotor processing and activation. Visual inspection and scoring of posture by a trained specialist is warranted and observational gait analysis or videography may be used in the determination of abnormal/normal gait mechanics [74]. Videography provides a permanent record of the child's performance that can subsequently digitally analyzed for quantitative evaluation of the patient. There are no standards for posture and gait analysis in pediatric cancer patients.

Flexibility can be assessed using a modified sit and reach test, but there is large experimental error with this measure. Additionally, ankle dorsiflexion with goniometers has been measured in children to assess lower limb extremity extensibility for proper foot mechanics [39].

Strength: As a proxy for total body strength, hand grip dynamometry has been used extensively. It requires minimal equipment and provides an estimation of overall strength. Other performance measures used in the pediatric cancer population include the timed get up and go test (TUG) and the $30 \mathrm{~s}$ chair test [40]. Both provide information on strength and neuromuscular coordination. 


\subsection{Quality of Life (QoL)}

Quality of life in both childhood and adult cancer patients has been well researched and there are a number of validated age-specific scales designed to assess the emotional, physical, and social aspects of one's life [21,45,53,56-58]. As part of a comprehensive rehabilitation plan for CCS, the authors support the importance of QoL assessment as part of the rehabilitation plan. The Pediatric Cancer Quality of Life Inventory is specific to this population and is a reliable tool [58].

\subsection{Nutrition}

Nutrition plays a critical role in normal growth and maturation and the client's diet should be ascertained during cancer treatment and age-appropriate nutritional guidelines for weight gain or to control obesity should be conveyed to the CCS caregiver [43-45]. Clinical dietitians are encouraged to be part of the pediatric cancer care team. Specifics of nutritional concerns for CCS are beyond the scope of this paper and are purposefully omitted.

\section{Guidelines for Exercise Prescription in Pediatric Cancer Patients}

Braam et al. provide the most current review of childhood and young adult cancer exercise training interventions during and after cancer [39]. In general, children need a minimal level of physical fitness for normal growth and development [50]. As cancer treatment often interrupts structured and unstructured physical activity during treatment, and physical activity and motor proficiency both during and after treatment have been shown to increase physical and mental wellbeing outcomes in childhood cancer patients, is seems reasonable to suggest that childhood cancer patients should engage in some physical activity during treatment and strive to reduce sedentary behavior. The extent of the physical activity is dependent on age, type of cancer and stage, and type of treatment and limitations caused by the disease itself or treatment complications [40]. For children who are extremely frail (osteopenic, immunosuppressed, low cardiorespiratory fitness), adjustments to the recommendations will need to be considered (less time, lower intensity and frequency, and smaller workloads).

Accordingly, the frequency, intensity, time, and type (FITT) of exercise used for healthy children may not apply to this population. Of the few studies published on exercise programs for childhood cancer patients, a combination of home-based ( $2 \times$ per week) and clinically based (hospital) programs $(1 \times$ per week) for approximately $60 \mathrm{~min}$ per session appears to work well [27,37-40,43,47]. For children who may not be able to attend a supervised exercise training session, home-based, parent-supervised exercise is considered appropriate $[39,40]$. It is important to note that parents of childhood cancer patients should be instructed on appropriate exercises and contraindications for their child and encouraged to participate with the child when exercising at home.

Exercise programs for childhood cancer patients in randomized control trials have both aerobic and resistance/strength training components [40]. Aerobic or endurance training appears to be tolerable with few adverse outcomes at a moderate intensity of 50-70\% age-predicted maximal heart rate for approximately $20 \mathrm{~min} / \mathrm{session}$ [40]. Resistance training in childhood cancer patients has consisted of traditional gym training equipment and a combination of 11-12 movements targeting major muscle groups (bench press, leg extension leg curl, shoulder press, leg press, abdominal crunch, arm curl, back extension, seated row, latissimus pulldown) [39,40]. Accommodations for children must be made when using exercise equipment designed for adults including proper body alignment within the machine, smaller free weights (less than $1 \mathrm{~kg}$ ), and proper supervision to ensure child safety.

\section{Recommendations}

In CCS, exercise training may be separated into three distinct phases with the understanding that the phases may overlap given the complexity of treatment, complications, and severity of the disease. The three-phase pediatric rehabilitation is presented schematically in Figure 1. Exercise guidelines for healthy children include the goal of $60 \mathrm{~min}$ of daily moderate to vigorous activity [75]; however, 
the duration and frequency in pediatric cancer patients will vary considerably. In phase I or ongoing treatment, it is suggested that exercise should be conservative and supervised. Medical oncology clearance for participation in structured activity is critical. In the early phase of exercise prescription, moving from sedentary behavior to any movement is the primary goal. This exercise may include walking under supervision, physical-therapy-assisted strength training or rehabilitation exercises following surgery. Aerobic exercise duration for CCS may start as low as 5-10 min daily based on health condition and progress with modest increases in session duration (e.g., $5 \mathrm{~min}$ ). Duration of exercise should be increased prior to increasing intensity of exercise and once a minimum of $30 \mathrm{~min}$ of continuous activity at low intensity is feasible, exercise intensity can be increased. Peak aerobic exercise intensity should be determined based on symptom-limited echocardiographic stress data. Most studies on exercise intensity for CCS are based on percentages of maximal heart rate $\left(50-70+\% \mathrm{HR}_{\max }\right)[39,40]$. In the absence of a peak exercise evaluation, exercise should start at $40-60 \%$ of heart rate reserve (HRR), using age-predicted maximal heart rates. As there is high variability in age-predicted maximal heart rates, adjustment to the exercise intensity should be made during the initial week of training. In the absence of any heart rate data, the use of RPE is relatively simple to use to gauge the intensity of exercise. Children should be encouraged to work at an intensity level between 1 and 5 on a 10-point RPE scale and not to exceed a level 6 during this phase. Heart rates corresponding to the appropriate RPE level can then be used in subsequent exercise sessions. Our approach to exercise intensity is somewhat conservative relative to other exercise trials in pediatric cancer patients but should be considered in the context of our health care model. Prior to each exercise session, the child should be adequately hydrated and properly nourished, and should avoid exercising in a hypoglycemic state. Additional considerations for testing and exercise training are presented in Table 2. 


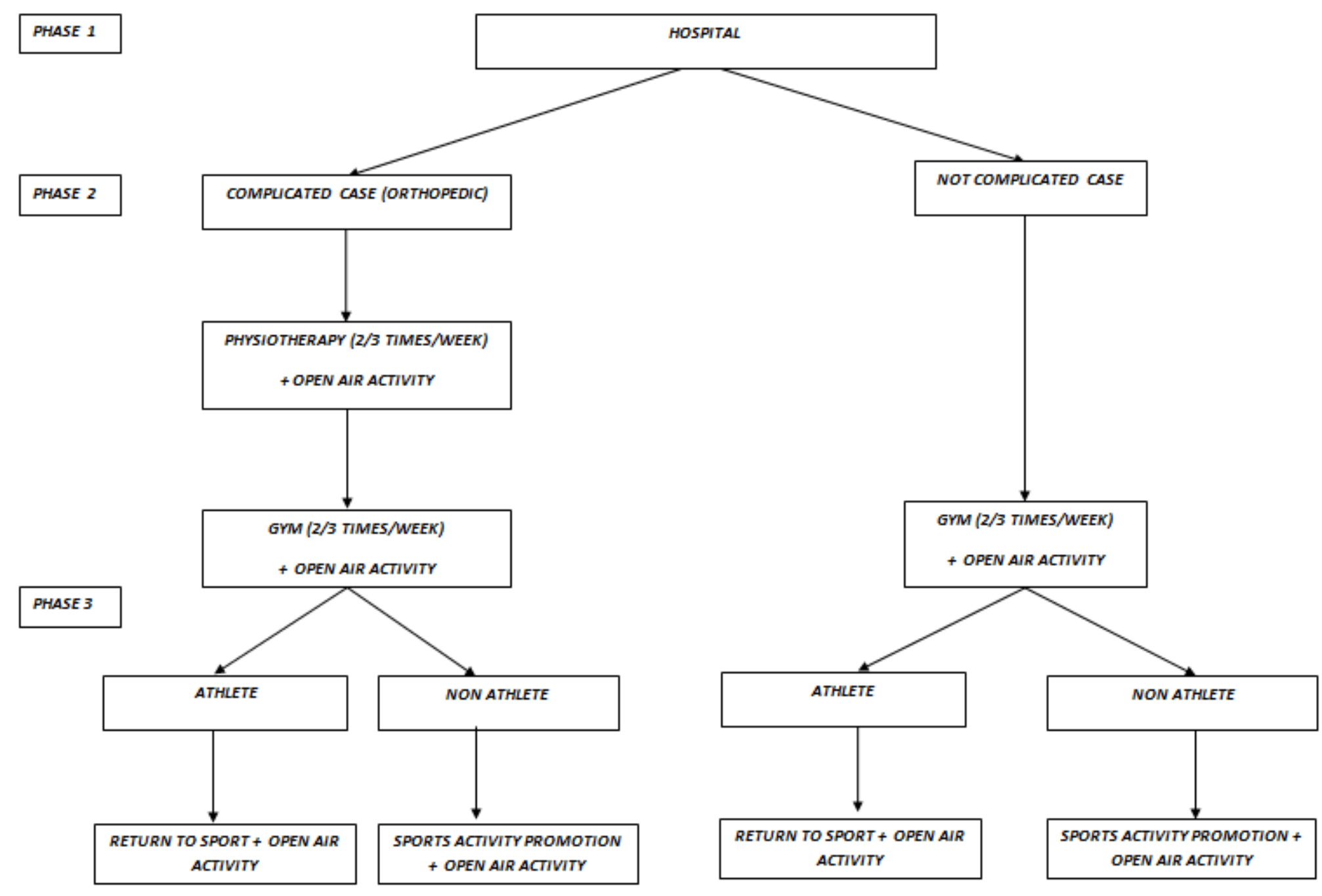

Figure 1. Flow-chart of the three-phase pediatric cancer rehabilitation. 
Table 2. Contraindications and precautions to exercise testing and training for patients with cancer.

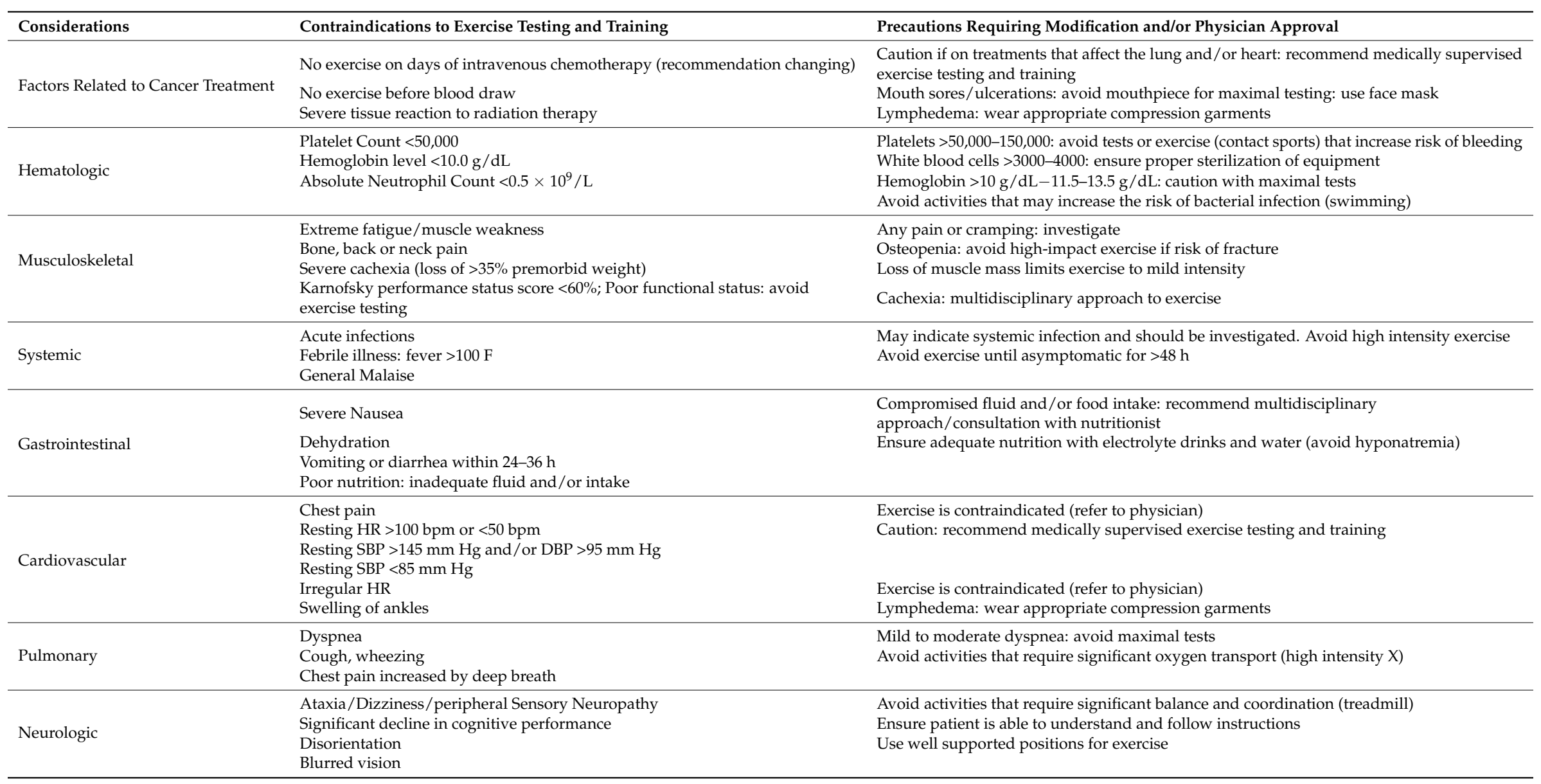

Adapted from McNeely et al. [76]. HR: heart rate; SBP: systolic blood pressure; DBP: diastolic blood pressure. 
Resistance training programs for CCS include body weight calisthenics, games of tag or wolf, obstacle course runs, and simple gymnastics. Emphasis should be placed on total body awareness and proprioceptive feedback. The primary goal in the initial phase of exercise prescription for CCS is to make the activity fun and promote motor skill development as motor skill proficiency is related to increased lifetime physical activity [77]. The programs need not be performance-based and careful instruction on movement patterns should be encouraged [72]. Adherence to specific sets and repetitions should be encouraged, while fatigue and improper postural alignment or biomechanics should serve as an indicator to terminate the specific exercise. Once proper movement patterns can be maintained for a specific exercise through an entire set of repetitions, the workload can then be increased either by adding more resistance or adding more repetitions per set.

In phase II, the CCS is moving from hospital-based exercise (professionally supervised) to a mixed home-based and parent-supervised program with the goal of ensuring patient stability. In phase II, aerobic conditioning duration should be extended from 30 to $45 \mathrm{~min}$ (multiple sessions per day is allowable) and each session should include a 5-min warm-up session and 5-min cooldown period at low intensity. The remainder of the session is designed to elicit a heart rate of $50-85 \%$ of peak exercise intensity determined at patient discharge. This corresponds to levels 1-7 on a 10-point RPE scale but no higher. In phase II, children should be encouraged to continue strength training (rehabilitation from orthopedic surgery or to correct muscle imbalances), add flexibility exercises where needed, and continue with sports specific motor skill development. Trial and error in motor skill development in the form of play is recommended and activities should be designed to be age-appropriate, entertaining, and fun. Gymnastics, swimming, and team sports (with precautions taken for contact sports) should be encouraged if the child is interested.

In phase III (at approximately 6-12 months post-discharge), CCS should be encouraged to participate in regular exercise for health maintenance or be cleared for regular sports participation. Clearance to move into competitive sports should be made by the oncology team and assessments made by Sports Medicine physicians. For those moving into competitive sports, assessment of mobility, joint stability, and movement patterns, followed by increased strength training, is recommended. Time dedicated to specific sports practice will then need to be individually determined.

In all three rehabilitation phases (hospital-based training, transition to home-based training, and competitive sports training), documentation of training should encouraged. A daily log of exercise should be maintained and relayed on a regular basis to the sports medicine team for review and ongoing adjustments to the exercise plan. Assessments should be made at the time of hospital discharge and after six and 12 months. A summary of each phase of the pediatric exercise rehabilitation plan is presented in Table 3. 
Table 3. Summary of phase I-III pediatric cancer rehabilitation.

\begin{tabular}{|c|c|c|c|c|}
\hline Phase & Where & Assessment & Exercise Plan & Comments \\
\hline \multirow{12}{*}{ I } & \multirow{12}{*}{ Hospital Based } & $\begin{array}{l}\text { Anthropometry: height, weight, BMI, head circumference, skinfolds and muscle circumferences. } \\
\text { Consult with dietitian and oncology team if patient appears malnourished. }\end{array}$ & \multirow{12}{*}{$\begin{array}{l}\text { Hospital based } \\
\text { under supervision. }\end{array}$} & Training plan: Emphasis on fundamental movements patterns (motor skill) and fun \\
\hline & & Orthopedic evaluation: Abnormal: refer to pediatric orthopedic team. & & \\
\hline & & Look for any obvious swellings or surgical scars. & & Modality: play (if possible), walking, cycle ergometer, stretching. \\
\hline & & $\begin{array}{l}\text { Assess for deformity: scoliosis, kyphosis, loss of lumbar lordosis or hyperlordosis of the lumbar } \\
\text { spine. Look for shoulder asymmetry and pelvic tilt. Postural scoliosis resolves on bending, } \\
\text { structural scoliosis does not resolve. }\end{array}$ & & Frequency $2-5 x$ per week \\
\hline & & Observe the patient walking to assess for any abnormalities of gait. & & Intensity: Low-to moderate HR \\
\hline & & Cardiopulmonary Exercise Testing (CPET) - Cycle ergometry, ECG, $\mathrm{O}_{2}$ saturation, HR, RPE. & & Duration: 5-60 min per session depending on status \\
\hline & & Power work capacity: Work capacity at Heart rate of $150 \mathrm{bpm}$ & & \\
\hline & & Pulmonary function testing: Spirometry & & Play: balance, agility, hopping, skipping, throwing \\
\hline & & Motor skill: Gait, Time up and go & & $\begin{array}{l}\text { Routine: Warm up exercises with body weight, play or aerobic exercise, strength exercises, } \\
\text { cool down. }\end{array}$ \\
\hline & & Flexibility: sit and reach & & Monitor $\mathrm{HR}, \mathrm{O}_{2}$ saturation if needed, dyspnea, $\mathrm{RPE}$, fatigue level \\
\hline & & Strength: Hand grip dynamometry, 30 s chair stand & & \\
\hline & & Quality of Life: PedQoL & & \\
\hline \multirow{10}{*}{ II } & \multirow{10}{*}{$\begin{array}{l}\text { Transition to } \\
\text { Home based }\end{array}$} & Assessment: Nurse, physical therapist, psychologist, cancer specialist in addition to medical team & \multirow{5}{*}{$\begin{array}{l}\text { Home-based under } \\
\text { parental supervision. }\end{array}$} & $\begin{array}{l}\text { Training plan: Emphasis on aerobic fitness, fundamental movements patterns } \\
\text { (motor skill) and fun }\end{array}$ \\
\hline & & $\begin{array}{l}\text { Anthropometry: height, weight, BMI, head circumference, skinfolds and muscle circumferences. } \\
\text { Consult with dietitian and oncology team if patient appears malnourished. }\end{array}$ & & Goal: return to normal activities and sport activities \\
\hline & & Power work capacity: Work capacity at Heart rate of $150 \mathrm{bpm}$ & & \\
\hline & & Pulmonary function testing: Spirometry & & Modality: play (if possible), walking, cycle ergometer, stretching. \\
\hline & & Motor skill: Gait, TUG & & Frequency: $3-5 x$ per week \\
\hline & & Flexibility: sit and reach & \multirow{5}{*}{$\begin{array}{l}\text { Education materials for } \\
\text { parents and siblings. }\end{array}$} & Intensity: Low-to moderate HR \\
\hline & & Strength: Hand grip dynamometry, $30 \mathrm{~s}$ chair stand & & Duration: 20-60 min per session depending on status \\
\hline & & & & Play: balance, agility, hopping, skipping, throwing \\
\hline & & & & $\begin{array}{l}\text { Routine: Warm up exercises with body weight, play or aerobic exercise, strength exercises, } \\
\text { cool down. }\end{array}$ \\
\hline & & & & Monitor HR and complete home exercise log. \\
\hline \multirow{10}{*}{ III } & \multirow{10}{*}{$\begin{array}{l}\text { Home based } \\
\text { and Independent }\end{array}$} & Assessment at 6 months and 12 months, 5, 10, 15 years (in addition to medical team) & \multirow{10}{*}{$\begin{array}{l}\text { Home-based } \\
\text { no supervision }\end{array}$} & Emphasis on strength, proficiency, postural control, cardiovascular conditioning and fun \\
\hline & & Anthropometry: height, weight, BMI, head circumference, skinfolds and muscle circumferences. & & Goal: return to normal activities and sport activities \\
\hline & & Power work capacity: Work capacity at Heart rate of $150 \mathrm{bpm}$ & & \\
\hline & & Pulmonary function testing: Spirometry & & Modality: play (if possible), walking, cycle ergometer, stretching, sports activities. \\
\hline & & Motor skill: Gait, TUG & & Frequency: 3-5x per week \\
\hline & & Flexibility: sit and reach & & Intensity: Low, moderate and vigorous $\mathrm{HR}$ \\
\hline & & Strength: Hand grip dynamometry, 30-s chair stand & & Duration: 30-60 min per session depending on status \\
\hline & & & & Play: team sports (football), swimming. \\
\hline & & & & $\begin{array}{l}\text { Routine: Warm up exercises with body weight, play or aerobic exercise, strength exercises, } \\
\text { cool down. }\end{array}$ \\
\hline & & & & Monitor HR and complete home exercise log. \\
\hline
\end{tabular}




\section{Conclusions}

The purpose of this paper was to present a review of childhood cancer types, associated cancer treatments, and late adverse events. The second aim was to suggest pediatric-specific assessments for childhood cancer patients in order to aid in the development of appropriate therapeutic exercise programs. The third aim was to outline a three-phased rehabilitation plan for childhood cancer patients. Contraindications and precautions for exercise testing and participation were also presented.

The population of childhood cancer survivors is likely to increase in the future and an important component of their treatment should be to optimize quality of life and reduce late adverse events by using exercise as a medicine. Research in pediatric oncology has clearly shown the positive impact of exercise interventions both during and after cancer treatment. In order to provide safe and efficacious exercise programs for childhood cancer patients, a multifactorial approach is necessary, which should include input from oncology and pediatric specialists from multiple disciplines: orthopedics, cardiology, endocrinology, pulmonology, sports medicine, psychology, nutrition, and exercise oncology specialists.

In order to provide pediatric oncology patients with safe programs, we propose a three-phase rehabilitation plan whereby phase I should be initiated in the hospital setting with physical therapists and cancer exercise specialists working in collaboration with the entire pediatric medical oncology team. In phase I rehabilitation for childhood cancer patients, the goal of increasing physical activity, avoiding sedentary behavior with an emphasis on motor skill acquisition, is paramount. Following patient discharge, in phase II rehabilitation (home-based exercise) a shift to aerobic, strength, flexibility, and motor skill refinement is the main goal and will require parental education and exercise supervision. In phase III (independent, unsupervised, or team sports) will require the involvement of parents, coaches, and regional specialists to successfully monitor the child's athletic development.

Conflicts of Interest: The authors declare no conflict of interest.

\section{References}

1. Steliarova-Foucher, E.; Colombet, M.; Ries, L.A.G.; Moreno, F.; Dolya, A.; Bray, F.; Hesseling, P.; Shin, H.Y.; Stiller, C.A. International incidence of childhood cancer, 2001-10: A population-based registry study. Lancet Oncol. 2017, 18, 719-731. [CrossRef]

2. American Cancer Society. Cancer Facts E Figures 2016; American Cancer Society: Atlanta, GA, USA, 2016.

3. Gatta, G.; Botta, L.; Rossi, S.; Aareleid, T.; Bielska-Lasota, M.; Clavel, J.; Dimitrov, N.; Jakab, Z.; Kaatsch, P.; Lacour, B.; et al. The EUROCARE Working Group Childhood cancer survival in Europe 1999-2007: Results of EUROCARE-5-A population based study. Lancet Oncol. 2014, 15, 35-47. [CrossRef]

4. Howlader, N.; Noone, A.M.; Krapcho, M.; Miller, D.; Bishop, K.; Kosary, C.L.; Yu, M.; Ruhl, J.; Tatalovich, Z.; Mariotto, A.; et al. (Eds.) SEER Cancer Statistics Review, 1975-2014; National Cancer Institute: Bethesda, MD, USA. Available online: https://seer.cancer.gov/csr/1975_2014/ (accessed on 4 April 2017).

5. Mosso, M.L.; Colombo, R.; Giordano, L.; Pastore, G.; Terracini, B.; Magnani, C. Childhood cancer registry of the province of Torino, Italy: Survival, incidence and mortality over 20 years. Cancer 1992, 69, 1300-1306. [CrossRef] [PubMed]

6. Armstrong, G.T.; Chow, E.J.; Sklar, C.A. Alterations in pubertal timing following therapy for childhood malignancies. In Endocrinopathy after Childhood Cancer Treatment; Wallace, W.H.B., Kelnar, C.J.H., Eds.; Karger Publishers: Basel, Switzerland, 2009; Volume 15, pp. 25-39.

7. Armstrong, G.T.; Stovall, M.; Robison, L.L. Long-term effects of radiation exposure among adult survivors of childhood cancer: Results from the Childhood Cancer Survivor Study. Radiat. Res. 2010, 174, 840-850. [CrossRef] [PubMed]

8. Bhatia, S.; Davies, S.M.; Baker, S.K.; Pulsipher, M.A.; Hansen, J.A. NCI, NHLBI first international consensus conference on late effects after pediatric hematopoietic cell transplantation: Etiology and pathogenesis of late effects after HCT performed in childhood-Methodologic challenges. Biol. Blood Marrow Transplant. 2011, 17, 1428-1435. [CrossRef] [PubMed] 
9. Clanton, N.R.; Klosky, J.L.; Li, C.; Jain, N.; Srivastava, D.K.; Mulrooney, D.; Zeltzer, L.; Stovall, M.; Robison, L.; Krull, K. Fatigue, vitality, sleep, and neurocognitive functioning in adult survivors of childhood cancer: A report from the childhood cancer survivor study. Cancer 2011, 117, 2559-2568. [CrossRef] [PubMed]

10. Diller, L.; Chow, E.J.; Gurney, J.G.; Hudson, M.M.; Kadin-Lottick, N.S.; Kawashima, T.I.; Leisenring, W.M.; Meacham, L.R.; Mertens, A.C.; Mulrooney, D.A.; et al. Chronic disease in the childhood cancer survivor study cohort: A review of published findings. J. Clin. Oncol. 2009, 27, 2339-2355. [CrossRef] [PubMed]

11. Feijen, E.A.M.; Font-Gonzalez, A.; van Dalen, E.C.; van der Pal, H.J.H.; Reulen, R.C.; Winter, D.L.; Kuehni, C.E.; Haupt, R.; Alessi, D.; Byrne, J.; et al. Late cardiac events after childhood cancer: Methodological aspects of the Pan-European study PanCareSurFup. PLoS ONE 2016, 11, e0162778. [CrossRef] [PubMed]

12. Friedman, D.L.; Whitton, J.; Leisenring, W.; Mertens, A.C.; Hammond, S.; Stoval, M.; Donaldson, S.S.; Meadows, A.T.; Robison, L.L.; Neglia, J.P. Subsequent neoplasms in 5-year survivors of childhood cancer: The childhood cancer survivor study. J. Natl. Cancer Inst. 2010, 102, 1083-1095. [CrossRef] [PubMed]

13. Gibson, T.M.; Robison, L.L. Impact of cancer therapy-related exposures on late mortality in childhood cancer survivors. Chem. Res. Toxicol. 2015, 28, 31-37. [CrossRef] [PubMed]

14. Haupt, R.; Jankovic, M.; Hjorth, L.; Skinner, R. Late effects in childhood cancer survivors and survivorship issues. Epidemiol. Prev. 2013, 37 (Suppl. 1), 1-296.

15. Lipshultz, E.R.; Holt, G.E.; Ramasamy, R.; Yechieli, R.; Lipshultz, S.E. Fertility, cardiac, and orthopedic challenges in survivors of adult and childhood sarcoma. Am. Soc. Clin. Oncol. Educ. Book 2017, 37, 799-806. [CrossRef] [PubMed]

16. Mulrooney, D.A.; Yeazel, M.W.; Kawashima, T.; Mertens, A.C.; Mitby, P.; Stovall, M.; Donaldson, S.S.; Green, D.M.; Sklar, C.A.; Robison, L.L.; et al. Cardiac outcomes in a cohort of adult survivors of childhood and adolescent cancer: Retrospective analysis of the Childhood Cancer Survivor Study cohort. BMJ 2009, 339, b4606. [CrossRef] [PubMed]

17. Oeffinger, K.C.; Mertens, A.C.; Sklar, C.A.; Kawashima, T.; Hudson, M.M.; Meadows, A.T.; Friedman, D.L.; Marina, N.; Hobbie, W.; Kadan-Lottick, N.S.; et al. Childhood Cancer Survivor Study. Chronic health conditions in adult survivors of childhood cancer. N. Engl. J. Med. 2006, 355, 1572-1582. [CrossRef] [PubMed]

18. Bhakta, N.; Liu, Q.; Yeo, F.; Baassiri, M.; Ehrhardt, M.J.; Srivastava, D.K.; Metzger, M.L.; Krasin, M.J.; Ness, K.K.; Hudson, M.M.; et al. Cumulative burden of cardiovascular morbidity in paediatric, adolescent, and young adult survivors of Hodgkin's lymphoma: An analysis from the St Jude Lifetime Cohort Study. Lancet Oncol. 2016, 17, 1325-1334. [CrossRef]

19. Carneiro Teixeira, J.F.; Maia-Lemos, P.D.S.; Cypriano, M.D.S.; Pellegrini, P.L. Obesity in survivors of childhood cancer: A review. Pediatr. Endocrinol. Rev. 2017, 15, 33-39. [PubMed]

20. Ligibel, J.A.; Alfano, C.M.; Courneya, K.S.; Demark-Wahnefried, W.; Burger, R.A.; Chlebowski, R.T.; Fabian, C.J.; Gucalp, A.; Hershman, D.L.; Hudson, M.M.; et al. American Society of Clinical Oncology position statement on obesity and cancer. J. Clin. Oncol. 2014, 32, 3568-3574. [CrossRef] [PubMed]

21. Fernandez-Pineda, I.; Hudson, M.M.; Pappo, A.S.; Bishop, M.W.; Klosky, J.L.; Brinkman, T.M.; Srivastava, D.K.; Neel, M.D.; Rao, B.N.; Davidoff, A.M.; et al. Long-term functional outcomes and quality of life in adult survivors of childhood extremity sarcomas: A report from the St. Jude lifetime cohort study. J. Cancer Surv. 2017, 11, 1-12. [CrossRef] [PubMed]

22. Gerber, L.H.; Hoffman, K.; Chaudhry, U.; Augustine, E.; Parks, R.; Bernad, M.; Mackall, C.; Steinberg, S.; Mansky, P. Functional outcomes and life satisfaction in long-term survivors of pediatric sarcomas. Arch. Phys. Med. Rehabil. 2006, 87, 1611-1617. [CrossRef] [PubMed]

23. Ridola, V.; Fawaz, O.; Aubier, F.; Bergeron, C.; de Vathaire, F.; Orbach, D.; Gentet, J.C.; Schmitt, C.; Dufour, C.; Oberlin, O. Testicular function of survivors of childhood cancer: A comparative study between ifosfamide and cyclophosphamide-based regimens. Eur. J. Cancer 2009, 45, 814-818.

24. Rose, S.R.; Danish, R.K.; Kearney, N.S.; Schreiber, R.E.; Lustig, R.H.; Burghen, G.A.; Hudson, M.M. ACTH deficiency in childhood cancer survivors. Pediatr. Blood Cancer 2005, 45, 808-813. [CrossRef] [PubMed]

25. Siviero-Miachon, A.A.; Spinola-Castro, A.M.; Guerra-Junior, G. Detection of metabolic syndrome features among childhood cancer survivors: A target to prevent disease. Vasc. Health Risk Manag. 2008, 4, 825-836. [PubMed] 
26. Skinner, R.; Mulder, R.L.; Kremer, L.C.; Hudson, M.M.; Constine, L.S.; Bardi, E.; Boekhout, A.; Borgmann-Staudt, A.; Brown, M.C.; Cohn, R.; et al. Recommendations for gonadotoxicity surveillance in male childhood, adolescent, and young adult cancer survivors: A report from the International Late Effects of Childhood Cancer Guideline Harmonization Group in collaboration with the PanCareSurFup Consortium. Lancet Oncol. 2017, 18, e75-e90.

27. Massimino, M.; Gandola, L.; Mattavelli, F.; Pizzi, N.; Seregni, E.; Pallotti, F.; Spreafico, F.; Marchianò, A.; Terenziani, M.; Cefalo, G.; et al. Radiation-induced thyroid changes: A retrospective and a prospective view. Eur. J. Cancer 2009, 45, 2546-2551. [CrossRef] [PubMed]

28. Hartman, A.; te Winkel, M.L.; van Beek, R.D.; de Muinck Keizer-Schrama, S.M.P.F.; Kemper, H.C.G.; Hop, W.C.J.; van den Heuvel-Eibrink, M.M.; Pieters, R. A randomized trial investigating an exercise program to prevent reduction of bone mineral density and impairment of motor performance during treatment for childhood acute lymphoblastic leukemia. Pediatr. Blood Cancer 2009, 53, 64-71. [CrossRef] [PubMed]

29. Hudson, M.M.; Mertens, A.C.; Yasui, Y.; Hobbie, W.; Chen, H.; Gurney, J.G.; Yeazel, M.; Recklitis, C.J.; Marina, N.; Robison, L.R.; et al. Health status of adult long-term survivors of childhood cancer: A report from the childhood cancer survivor study. JAMA 2003, 290, 1583-1592. [CrossRef] [PubMed]

30. Hudson, M.M.; Ness, K.K.; Gurney, J.G.; Mulrooney, D.A.; Chemaitilly, W.; Krull, K.R.; Green, D.M.; Armstrong, G.T.; Nottage, K.A.; Jones, K.E.; et al. Clinical ascertainment of health outcomes among adults treated for childhood cancer. JAMA 2013, 309, 2371-2381. [CrossRef] [PubMed]

31. Skinner, R. Nephrotoxicity—What do we know and what don't we know? J. Pediatr. Hematol. Oncol. 2011, 33, 128-134. [CrossRef] [PubMed]

32. Sklar, C.A.; Mertens, A.C.; Mitby, P.; Whitton, J.; Stovall, M.; Kasper, C.; Mulder, J.; Green, D.; Nicholson, H.S.; Yasui, Y.; et al. Premature menopause in survivors of childhood cancer: A report from the childhood cancer survivor study. J. Natl. Cancer Inst. 2006, 98, 890-896. [CrossRef] [PubMed]

33. Interiano, R.B.; Kaste, S.C.; Li, C.; Srivastava, D.K.; Rao, B.N.; Warner, W.C.Jr.; Green, D.M.; Krasin, M.J.; Robison, L.L.; Davidoff, A.M.; Hudson, M.M.; et al. Associations between treatment, scoliosis, pulmonary function, and physical performance in long-term survivors of sarcoma. J. Cancer Surv. 2017, 11. [CrossRef] [PubMed]

34. Ness, K.K.; Armstrong, G.T.; Kundu, M.; Wilson, C.L.; Tchkonia, T.; Kirkland, J.L. Frailty in childhood cancer survivors. Cancer 2015, 121, 1540-1547. [CrossRef] [PubMed]

35. Ness, K.K.; Krull, K.R.; Jones, K.E.; Mulrooney, D.A.; Armstrong, G.T.; Green, D.M.; Chemaitilly, W.; Smith, W.A.; Wilson, C.L.; Sklar, C.A.; et al. Physiologic frailty as a sign of accelerated aging among adult survivors of childhood cancer: A report from the St Jude Lifetime Cohort Study. J. Clin. Oncol. 2013, 31, 4496-4503. [CrossRef] [PubMed]

36. Winther, J.F.; Kenborg, L.; Byrne, J.; Hjorth, L.; Kaatsch, P.; Kremer, L.C.; Kuehni, C.E.; Auquier, P.; Michel, G.; de Vathaire, F.; et al. Childhood cancer survivor cohorts in Europe. Acta Oncol. 2015, 54, 655-668. [CrossRef] [PubMed]

37. Wilson, C.L.; Chemaitilly, W.; Jones, K.E.; Kaste, S.C.; Srivastava, D.K.; Ojha, R.P.; Yasui, Y.; Pui, C.-H.; Robison, L.L.; Hudson, M.M.; et al. Modifiable factors associated with aging phenotypes among adult survivors of childhood acute lymphoblastic leukemia. J. Clin. Oncol. 2016, 34, 2509-2515. [CrossRef] [PubMed]

38. Schmitz, K.H.; Courneya, K.S.; Matthews, C.; Demark-Wahnefried, W.; Galvão, D.A.; Pinto, B.M.; Irwin, M.L.; Wolin, K.Y.; Segal, R.J.; Lucia, A.; et al. American College of Sports Medicine roundtable on exercise guidelines for cancer survivors. Med. Sci. Sports Exerc. 2010, 42, 1409-1426. [CrossRef] [PubMed]

39. Braam, K.I.; van der Torre, P.; Takken, T.; Veening, M.A.; van Dulmen-den Broeder, E.; Kaspers, G.J.L. Physical exercise training interventions for children and young adults during and after treatment for childhood cancer. Cochrane Database Syst. Rev. 2013, 4. [CrossRef]

40. Huang, T.-T.; Ness, K.K. Exercise interventions in children with cancer: A review. Int. J. Pediatr. 2011, 1-11. [CrossRef]

41. Deisenroth, A.; Söntgerath, R.; Schuster, A.J.; von Busch, C.; Huber, G.; Eckert, K.; Kulozik, A.E.; Wiskemann, J. Muscle strength and quality of life in patients with childhood cancer at early phase of primary treatment. Pediatr. Hematol. Oncol. 2016, 33, 393-407. [CrossRef] [PubMed] 
42. Esbenshade, A.J.; Friedman, D.L.; Smith, W.A.; Jeha, S.; Pui, C.H.; Robison, L.L.; Ness, K.K. Feasibility and initial effectiveness of home exercise during maintenance therapy for childhood acute lymphoblastic leukemia. Pediatr. Phys. Ther. 2014, 26, 301-307. [CrossRef] [PubMed]

43. Keats, M.R.; Culos-Reed, S.N. A community-based physical activity program for adolescents with cancer (project TREK): Program feasibility and preliminary findings. J. Pediatr. Hematol./Oncol. 2008, 30, 272-280. [CrossRef] [PubMed]

44. Rueegg, C.S.; Michel, G.; Wengenroth, L.; von der Weid, N.X.; Bergstraesser, E.; Kuehni, C.E. Physical performance limitations in adolescent and adult survivors of childhood cancer and their siblings. PLOS ONE 2012, 7, e47944. [CrossRef] [PubMed]

45. Wurz, A.; Brunet, J. The effects of physical activity on health and quality of life in adolescent cancer survivors: A systematic review. JMIR Cancer 2016, 2, e6. [CrossRef] [PubMed]

46. Zhang, F.F.; Kelly, M.J.; Aviva, M. Early nutrition and physical activity interventions in childhood cancer survivors. Curr. Obes. Rep. 2017, 6, 168-177. [CrossRef] [PubMed]

47. Zhang, F.F.; Meagher, S.; Scheurer, M.; Folta, S.; Finnan, E.; Criss, K.; Economos, C.; Dreyer, Z.; Kelly, M. Developing a web-based weight management program for childhood cancer survivors: Rationale and methods. JMIR Res. Protoc. 2016, 5, e214. [CrossRef] [PubMed]

48. Zhang, F.F.; Parsons, S.K. Obesity in childhood cancer survivors: Call for early weight management. Adv. Nutr. 2015, 6, 611-619. [CrossRef] [PubMed]

49. Fairey, A.S.; Courneya, K.S.; Field, C.J.; Mackey, J.R. Physical exercise and immune system function in cancer survivors: A comprehensive review and future direction. Cancer 2002, 94, 539-551. [CrossRef] [PubMed]

50. Malina, R.M.; Bouchard, C.; Bar-Or, O. Growth, Maturation, and Physical Activity, 2nd ed.; Human Kinetics: Champaign, IL, USA, 2004; pp. 3-18.

51. Li, T.; Wei, S.; Shi, Y.; Pang, S.; Qin, Q.; Yin, J.; Deng, Y.; Chen, Q.; Wei, S.; Nie, S.; et al. The dose-response effect of physical activity on cancer mortality: Findings from 71 prospective cohort studies. Br. J. Sports Med. 2016, 50, 339. [CrossRef] [PubMed]

52. Hjorth, L.; Haupt, R.; Skinner, R.; Grabow, D.; Byrne, J.; Karner, S.; Levitt, G.; Michel, G.; van Der Pal, H.; Bárdi, E.; et al. Survivorship after childhood cancer: PanCare: A European network to promote optimal long-term care. Eur. J. Cancer 2015, 1, 1203-1211. [CrossRef] [PubMed]

53. Wallace, W.H.; Blacklay, A.; Eiser, C.; Davies, H.; Hawkins, M.; Levitt, G.A.; Jenney, M.E.M. Regular review: Developing strategies for long term follow up of survivors of childhood cancer. BMJ 2001, 323, 271-274. [CrossRef] [PubMed]

54. American Academy of Pediatrics Section on Hematology/Oncology, Children's Oncology Group Long-Term Follow-Up Care for Pediatric Cancer Survivors. Pediatrics 2009, 123, 906-915. [CrossRef]

55. Castellino, S.M.; Ullrich, N.J.; Whelen, M.J.; Lange, B.J. Developing interventions for cancer-related cognitive dysfunction in childhood cancer survivors. J. Natl. Cancer Inst. 2014, 106, 1-16. [CrossRef] [PubMed]

56. Langeveld, N.E.; Grootenhuis, M.A.; Voûte, P.A.; de Haan, R.J.; van den Bos, C. Quality of life, self-esteem and worries in young adult survivors of childhood cancer. Psychooncology 2004, 13, 867-881. [CrossRef] [PubMed]

57. Huang, I.-C.; Brinkman, T.M.; Armstrong, G.T.; Leisenring, W.; Robison, L.L.; Krull, K.R. Emotional distress impacts quality of life evaluation: A report from the Childhood Cancer Survivor Study. J. Cancer Surv. 2017, 11, 309-319. [CrossRef] [PubMed]

58. Varni, J.W.; Katz, E.R.; Seid, M.; Quiggins, D.J.L.; Friedman-Bender, A. The pediatric cancer quality of life inventory-32 (PCQL-32). Cancer 1998, 82, 1184-1196. [CrossRef]

59. The Children's Oncology Group. Long-Term Follow-Up Guidelines for Survivors of Childhood, Adolescent, and Young Adult Cancers. Available online: http://www.survivorshipguidelines.org/ (accessed on 20 December 2017).

60. Lohman, T.G.; Roche, A.F.; Martorell, R. (Eds.) Anthropometric Standardization Reference Manual; Human Kinetics; Information Systems Division, Naional Agricultural Library: Champaign, IL, USA, 1988.

61. Stewart, A.; Marfell-Jones, M. International Standards for Anthropometric Assessment; International Society for the Advancement of Kinanthropometry: Lower Hutt, New Zealand, 2011.

62. Roche, A.F.; Malina, R.M. Manual of Physical Status and Performance in Childhood; Plenum Press: New York, NY, USA, 1983; p. 1. 
63. Bachrach, L.K.; Sills, I.N. Clinical report-bone densitometry in children and adolescents. Pediatrics 2011, 127, 189-194. [CrossRef] [PubMed]

64. Cox, C.1.; Zuh, L.; Ojha, R.P.; Steen, B.D.; Ogg, S.; Robison, L.L.; Hudson, M.M. Factors supporting cardiomyopathy screening among at-risk adult survivors of pediatric malignancies. Support Care Cancer 2017, 25, 1307-1316. [CrossRef] [PubMed]

65. Golden, E.; Beach, B.; Hastings, C. The pediatrician and medical care of the child with cancer. Pediatr. Clin. N. Am. 2002, 49, 1319-1338. [CrossRef]

66. Stefani, L.; Pedrizzetti, G.; Galanti, G. Clinical application of 2D speckle tracking strain for assessing cardio-toxicity in oncology. J. Funct. Morphol. Kinesiol. 2016, 1, 343-354. [CrossRef]

67. Voigt, J.U.; Pedrizzetti, G.; Lysyansky, P.; Marwick, T.M.; Houle, H.; Baumann, R.; Pedri, S.; Ito, Y.; Abe, Y.; Metz, S.; et al. Definitions for a common standard for 2D Speckle tracking echocardiography: Consensus document of the EACVI/ASE/industry task force to standardize deformation imaging. Eur. Heart J. Cardiovasc. Imaging 2015, 16,1-11. [CrossRef] [PubMed]

68. Yu, A.F.; Raikhelkar, J.; Zabor, E.C.; Tonorezos, E.S.; Moskowitz, C.S.; Adsuar, R.; Mara, E.; Huie, K.; Oeffinger, K.C.; Steingart, R.M.; et al. Two-dimensional speckle tracking echocardiography detects subclinical left ventricular systolic dysfunction among adult survivors of childhood, adolescent, and young adult cancer. Cancer Biomed. Res. Int. 2016. [CrossRef] [PubMed]

69. Leger, L. Aerobic performance. In Measurement in Pediatric Exercise Science; Dougherty, D., Ed.; Human Kinetics: Champaign, IL, USA, 1996; pp. 183-223.

70. Borg, G.; Hassmen, P.; Whipp, B.J. Perceived exertion in relation to heart rate and blood lactate 12 during and arm and leg exercise. Eur. J. Appl. Physiol. 1985, 65, 679-685.

71. Bayley, N. Bayley scales of infant and toddler development: Administration manual. In Harcourt Assessment; Pearson: San Antonio, TX, USA, 2006.

72. Naumann, F.L.; Hunt, M.; Ali, D.; Wakefield, C.E.; Moultrie, K.; Cohn, R.J. Assessment of fundamental motor skills in childhood cancer patients. Pediatr. Blood Cancer 2015, 62, 2211-2215. [CrossRef] [PubMed]

73. Moultrie, K.; Cohn, R.J. Assessment of gross motor skills and phenotype profile in children 9-11 years of age in survivors of acute lymphoblastic leukemia. Pediatr. Blood Cancer 2015, 1, 46-52. [CrossRef]

74. Perry, J.; Davids, J.R. Gait analysis: Normal and pathological function. J. Pediatr. Orthop. 1992, $126,815$. [CrossRef]

75. U.S. Department of Health and Human Services. Physical Activity Guidelines for Americans; Department of Health and Human Services: Washington, DC, USA, 2008.

76. McNeely, M.L.; Peddle, C.J.; Parliament, M.; Courneya, K.S. Cancer rehabilitation: Recommendations for integrating exercise programming in a clinical setting. Curr. Cancer Ther. Rev. 2006, 2, 251-260. [CrossRef]

77. Malina, R.M. Movement proficiency in childhood: Implications for physical activity and youth sport. Kinesiol. Slov. 2012, 18, 19-34.

(C) 2018 by the authors. Licensee MDPI, Basel, Switzerland. This article is an open access article distributed under the terms and conditions of the Creative Commons Attribution (CC BY) license (http://creativecommons.org/licenses/by/4.0/). 